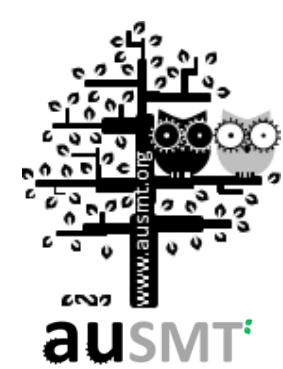

\title{
Continued Evolution of Automated Manufacturing - Cloud-Enabled Digital Manufacturing
}

\section{Chung-Hung Huang*}

Industrial Economics and Knowledge Center (IEK), Industrial Technology Research Institute (ITRI), Taiwan

(Received 9 February 2015; Published on line 1 March 2015)

*Corresponding author email: yyhuang@itri.org.tw

DOI: $10.5875 /$ ausmt.v5i1.861

Abstract: In contrast to conventional manufacturing, digital manufacturing is not affected by marginal costs; that is, the cost for producing a single prototype is not different from producing several thousand ones. Digital manufacturing consequently eliminates the requirement for large sums of capital necessary for conventional manufacturing. Digital manufacturing combined with cloud platforms and cloud-enabled databases will allow large-quantity virtual product development while minimizing costs, which will consequently reflect on the efficient manufacturing of physical products.

Keywords: Digital manufacturing, cloud-enabled database, 3D printing, robots

\section{The Digital Manufacturing Reform}

General Motors introduced the first industrial robot in 1961. Telephone operators were completely replaced in the 1960's. American Airlines launched its reservation system in the 1970's. Product barcode scanners and automated teller machines emerged in stores and banks in the late 1970's. The personal computer with word processing and spreadsheet functionality was introduced in the mid 1980's. The Internet and e-commerce rapidly advanced following 2000, developments that are more recent and more familiar to us. Starting 2010, information and communication technology as a whole has entered an era of high maturity.

Since the proposal of Moore's Law, its effect has been reflected in the processors, memory chips, sensors, and other computer hardware components that have been continuously developed and improved. Not only have computers become faster in terms of processing speed, they have become cheaper and more compact, and can now achieve feats thought to be impossible. The current rise of digital manufacturing will inevitably induce a reform far greater than the emergence of the Internet over a decade ago. Following the technological progression from the ubiquity of personal computers and the Internet to the rise of blogs and social media, the most apparent trend of the present and future in digital reform is and will be its expansion into the manufacturing industry.

The greatest feature of digital manufacturing, which is rumored to initiate the third industrial revolution, is the ability to rapidly provide customized products and services to consumers, resolving the 3 major flaws of conventional manufacturing. In conventional manufacturing, economies of scale is necessitated to lower marginal costs, which forces manufacturers to enter mass production in order to earn profit; manufacturing is extremely time consuming; and errors in manufacturing processes result in substantial losses for the manufacturer.

Compared to conventional factories, digital manufacturing is not affected by marginal costs. Cost of manufacturing is fixed, regardless of producing a single prototype or several thousand ones. Therefore, bulk orders are not required for initiating production. Digital manufacturing further eliminates the requirement for large sums of capital necessary for conventional manufacturing. Digital manufacturing combined with cloud platforms and cloud-enabled databases will allow large-quantity virtual product development while minimizing costs, which will consequently reflect on the efficient manufacturing of physical products. 


\section{Cloud-Based Digital Manufacturing Shapes the Future of the Manufacturing}

The emergence and implementation of digital manufacturing may potentially eliminate the requirement for investing large amount of capital into design, creating molds, mass production, and establishing distribution channels in conventional manufacturing industries. Among the various branches of manufacturing, business involved in the production of metal hand tools would be one of the first to experience the changes brought by digital manufacturing, these industries include plumbing hardware, metal hand tools, and bicycle parts manufacturers.

In scope of metal spanner manufacturing in Taiwan, which generates an annual export value of approximately NT\$50 billion, numerous production procedures, such as development and manufacturing procedures, machining, and automation system implementation (e.g., mechanical arms, machine vision, and jaws) are initiated primarily based on the experience of professionals assisted with computer-aided design (CAD) software. Following the implementation of automated production, the compatibility of the various software and hardware including sensors in the automated system, such as the retrieval, grinding, polishing, and discharging of workpieces, can only be verified once designs have been contracted. However, when problems are identified after production has initiated, the revision and redesign of the automated system, re-development of relevant software, and repeated debugging and adjusting greatly increase manufacturing time as well as additional material and labor costs before the products are delivered.

Using simulation analysis supplemented by cloud-enabled databases, the quality and efficiency of product design, production, and machining can be elevated. The content of simulation analysis supplemented by cloud-enabled databases for digital manufacturing includes:

1. Digital simulation techniques to virtually simulate the physical and lighting effects of workpieces during processing and the collision kinetics and deformation responses of rigid and non-rigid bodies;

2. 3D model Cloud databases that are capable of accurately present the digital models of processed workpieces and the digital models of the automated equipment during processing; and

3. Virtual spaces, such as object databases correction of processing parameters, and feedback, to

Chung-Hung Huang is a researcher in the Machinery \& System Research Division at Industrial Economics and Knowledge Center. His research interests are focused on industry analysis for automated machinery and equipment. accelerate the integration between design and production systems and to timely assess the performance of these systems. Virtual manufacturing techniques will inevitably transcend the spatial limitations that challenge manufacturers when establishing production lines.

The competitiveness of developing metal products can be increased through the digital design manufacturing technology integrating virtuality and reality. By combining the virtual manufacturing design and simulation of digital manufacturing platforms and the added value of software, systems, and services, the time required to develop products can be reduced while ensuring quality and increasing yield, thereby mitigating spatial limitations and promoting the intelligent manufacturing of high-value products. Digital manufacturing not only influences the costs and manufacturing procedures, but also reshapes the entire industrial structure and blurs the various roles within the supply chain. In other words, supply chains will become more simple and localized and enterprises can more flexibly transition into a new era of manufacturing that demands diversified and customized products in small quantities.

\section{The Importance of 3D Printing and Robots}

In conventional machine manufacturing, the production of metal components requires several days just for designing and molding the product. Nowadays, the availability of open-source hardware and software enables manufacturers with computational customization equipment to complete sample production within a day, greatly reducing production costs and facilitating producers in innovating their products. However, the supply chain, as defined in the previous section, must also achieve a new level of integration in aspects of strategizing, design, and execution. In addition, enterprises must also formulate new plans when collaborating with partners or servicing customers. As product development cycles are gradually reduced and creativity innovates, the supply chains of future Taiwanese manufacturers must detach themselves from conventional price-by-quantity and profit-by-turnover business models. For example, the conventional supply chains for smartphones require orders of several million units to open a production line. By contrast, an open-source smartphone product can be rapidly mass-produced using cloud-enabled digital manufacturing with an order of 35,000 users.

Taiwan's manufacturing industry is renowned for its flexibility. In the past, the electronics industry of Taiwan shaped global trade flows and created solid 
industrial structures based on the principles of economies of scale and with multi-level and globalized supply chains. Now, the prevalence of 3D printing, smart robots, and digital manufacturing based on open-source codes have initiated a novel reform in the manufacturing industry, transforming the previously hardware-defined industry to one that is based on software.

In an ever-changing industrial environment, the pursuits of manufacturing are nothing less than the maximization of quality, reasonable and reliable production processes, the reduction of resource wastage, and safe and secure production workflows. Subsequently, the development of electronic and automated equipment throughout the years is to satisfy these pursuits. The core purpose of such development is to reduce the unnecessary variability caused by producers and standardize production processes. The manufacturing development plans proposed by numerous industrial countries, such as the Advanced Manufacturing Plan proposed by the United States, which anticipates 3D printing, big data systems, and advanced robotics to be the key manufacturing models of the future; the German Industry 4.0; the human-machine co-existing factories of the future introduced by Japan; and the Thirteenth Five-Year Development Plan proposed by China, show that smart manufacturing will be the core development for modern manufacturing. Subsequently, automated equipment, such as 3D printing and robots, play a key role in this development.

According to the statistics announced by Wohlers Associates, an American-based company specializing in additive manufacturing techniques and technological consultation services, the global 3D printing industry was extremely successful in 2013, achieving a market size of US\$ 3 billion with a $36 \%$ growth compared to the previous year. Subsequently, experts project the market size for 2014 to exceed US\$ 4 billion and growth over $30 \%$. Due to the exceptional market performance in 2013, Wohlers projected their forecasts to 2020 , predicting that the 3D printing industry will reach US\$ 21 billion with a compound annual growth rate (CAGR) of approximately 31\% from 2013 to 2020.

The supply chains essential for optimizing efficiency may be replaced or eliminated with the prevalence of 3D printing. Following technological advancements and the release of patents, 3D printing may enter mass production within 5 years, reducing average cost of manufacturing by $79 \%$, with the prospect of a $90 \%$ reduction within a decade. Predicting the future of 3D printing technology, experts believe that (1) the market will continue to grow; (2) the involvement of leading international manufactures in various industries will change the industrial ecology in a short frame of time; (3) the direct manufacturing of metal components will gradually become possible; and (4) although 3D printing is not a panacea, its fields of application will gradually expand.

Another benefit of digital manufacturing is the ability to set the learning capacity of smart robots through software, thereby replacing complex mechanical operations with artificial intelligence. Although prices for labor can be suppressed through extant globalized supply chains, management of these supply chains has been one of the greatest problems for enterprises. With the gradual reduction in smart robot prices and advancement in relevant technologies, the implementation of smart robots into manufacturing will inevitably increase production efficiency and localizing production. Moreover, in a manufacturing environment that is gradually transitioning from component assembly processes into module assembly, smart machines can better complete actions that are highly complex or require a high level of accuracy than manual labor. They can be deeply integrated into production lines and flexibly operated through software, facilitating rapid market integration and satisfying the demand for small-quantity manufacturing at reasonable prices.

Under a limited domestic market size, Taiwanese robot manufacturers should develop strategies that adopt the domestic market as a test market to comprehensively understand the market demands in application. Outcomes can be used as a reference when expanding into European or the US markets. With regards to competitiveness, a comprehensive and close-knit machine tool industry can enhance the fundamental advantages of applying Taiwanese automated equipment. Looking forward, problems concerning the return of Taiwanese manufacturers and labor shortage following changes in the domestic industrial investment environment will directly correlate to the new era of automated manufacturing. As hardware technologies and system integration capacity in Taiwan is nearing fully mature, Taiwanese industries are suggested to accelerate the coverage of automated system integration services concerning eye-hand robot technologies and products, and continue to build and reinforce cloud-enabled digital manufacturing. Taiwan should endeavor to differentiate its development of digital manufacturing from other advanced countries, such as Japan and the U.S. To achieve this, "revolutionary reform" strategies should be employed, where products or manufacturing techniques are introduced by specific industries. Taiwanese manufacturers must endeavor to reform in a distinctive and revolutionary fashion to constantly remain competitive. 
After the financial tsunami, the argument for industry automation pointed out - "The only way of survival at present is for the manufacturing industry to introduce automation with robots at its core", does have its reasoning, but looking at it from another angle and faced with a practical issue, governments all over the word will have to face the impact brought by the robotic evolution toward industries and work opportunities for the low-middle class workers. Practical and workable measures need to be supplemented to help this working class to adjust and join in this evolutionary change. Otherwise, the changes brought by automation industrial technology will be incomparable to the negative impact it brings to the labor market. The issue on competition to the labor force will be a global topic not only for the low-middle class technicians in developed countries, it will also cover the relatively cheaper labor force in developing and emerging countries. Under the wave of global capitalism, the impact brought upon by robots will be greater on the latter, and the impact on the labor market and working class structure as a whole will be intense. This is also a profound issue that requires consideration with the advancement of robotics technology and robust development of business opportunities. Establishing such an information platform would provide complete market intelligence for Taiwanese robotic or component businesses, thereby helping them discover and seize business opportunities. 